\title{
Universiteit
}

Leiden

The Netherlands

\section{Nominal number in cushitic}

Mous, M.P.G.M.; Cabredo Hofherr, P.; Doetjes, J.S.

\section{Citation}

Mous, M. P. G. M. (2021). Nominal number in cushitic. In P. Cabredo Hofherr \& J. S. Doetjes (Eds.), Oxford Handbooks Series (pp. 522-538). Oxford: Oxford University Press. doi:10.1093/oxfordhb/9780198795858.013.25

Version: $\quad$ Publisher's Version

License:

Licensed under Article 25fa Copyright Act/Law (Amendment Taverne)

Downloaded from:

Note: To cite this publication please use the final published version (if applicable). 


\title{
NOMINAL NUMBER \\ IN CUSHITIC
}

\author{
MAARTEN MOUS
}

\subsection{INTRODUCTION}

IN order to characterise Number in Cushitic it is essential to examine it from three angles: (i) number neutrality or the optionality of marking number, discussed in section 25.2, (ii) morphological number marking on nouns, discussed in section 25.3 , and (iii) number as an agreement category, discussed in section 25.5. Number is not obligatorily expressed in various Cushitic languages; that is, the noun has a general number form that is unspecified for number. Number marking on the noun, though in some languages not often used, can be very complex with singulative formatives in addition to many different plural formatives. Number formatives impose gender and in Somali this has resulted in apparent gender polarity (singular and plural having opposite values for gender), discussed in section 25.4. Number agreement occurs on adjectives in some Cushitic languages, not in all. These languages show two agreement systems on adjectives: to number and to gender. I will argue that subject agreement on the verb is to gender rather than to number in many Cushitic languages and this leads to the intriguing situation of plural as a value for the category of gender as argued for in section 25.6. The overall character of the categories of number and gender is discussed in the concluding section 25.7. Rather than providing a typological characterization of Cushitic, I present some interesting cases. Bear in mind that every Cushitic language has its own characteristics.

\subsection{NUMBER NEUTRALITY}

Number is a category that tends not to be obligatorily expressed on the noun in Cushitic languages and thus nouns can have 'general' number (Corbett, 2000: 9-19). 
Nevertheless, Cushitic languages have a variety of nominal plural markers and the various languages differ in how commonly these plural-marked nouns are used. In Somali, Oromo, and some other Cushitic languages no plural form of a noun is used if plurality of the nominal constituent is already evident from the presence of a numeral. Crass (2005: 70) makes the observation that the derived plural forms are rarely used in K'abeena; the form that is not marked for number is used as general number. A sentence like (1) with a general number subject and a general number object can refer to any number of thieves and cows. The agreement on the verb is with the masculine gender of the subject. However, if the verb conjugation in (1) takes the form 'aa'ito 'she/they took', then the subject is automatically interpreted as plural.

(1) faangoo lalu 'aa'iyo

(K'abeena)

thief.M.NOM cattle:ACC take:PF:3SG.M

'A/the thief/thieves steal a/the cow/cows.'

(Crass, 2005: 65)

Oromo is well known for its use of a general number form. In example (2a) the noun is in its base form and has plural interpretation as is evident from the numeral 'three' in the constituent. Both the nominal modifier (demonstrative) and the verb agree with the masculine gender of the subject noun. Also without a numeral the base noun can have plural reference as in $(2 \mathrm{~b})$. There is dialectal variation between gender or number subject agreement: in Harar Oromo (2c) such a masculine subject noun triggers masculine agreement within the nominal constituent on the relative marker but plural agreement on the verb, and the adjective 'beautiful'.

(2) a. minn-ini

sadeeni kuu house.M-NOM three DEM.PROX.M:SUBY 'These three houses have collapsed.'

haa jig-e (Borana Oromo)

b. gabri-ini mar-s-ee FOC collapse-3M.SG:PAST

(Stroomer, 1987: 61)

(Borana Oromo)

Somali.M-NOM go.round-CAUS-3M.SG:PAST

'The Somalis have surrounded [them].'

(Stroomer, 1987: 224)

c. dubrii lameen xa saree ark-an bareed-oo

$(\text { Harar Oromo })^{1}$ women.M.NOM two REL.M dog see-PL beautiful-PL

'Two women who saw a dog, are beautiful.'

(Clamons, 1992: 58)

Analyses of Cushitic languages often equate the morphologically simple base noun with general number. Yet this generalization may be too simple. Andrzejewski (1960: 73) points out that in (Borana) Oromo base forms are indeed often associated with neither-plurality-nor-singularity notionally but not always: certain nouns in their base

'Clamons (1992: 58) has dubrii as a plural form (in nominative case and hence ii) with 'women' as gloss and as feminine even though the relative pronoun is masculine (and feminine $t a$ is ungrammatical here). Owens (1985: 258) has dubrá (f) 'girl', dubrii (f) 'cousin' in Harar Oromo. Andrzejewski (1960: 73) has for Borana Oromo dubra 'girls' as an example of general forms that are notionally plural. 
form are associated with groups of domestic animals or people and hence with plurality (lôn ${ }^{i}$ 'cattle', $d u b r^{a}$ ' girls'), while for other words for domestic animals or people the base form denotes one individual only and hence singularity (niiti' 'woman', sánga' 'fat $\left.o x^{\prime}\right){ }^{2}$ There is an urgent need for a comprehensive study of the pragmatics of the use of various number forms in the Cushitic languages (general number, derived plural, derived singular). A cursory look at Konso stories in my collection suggests that the choice of number form is not only dictated by the criterion of whether the number value is prominent at that point in the story or not.

Plurality as such is not enough to trigger plural agreement in Oromo it seems. The plural derived subject 'oxen' in (3) triggers feminine agreement on the verbs 'become bad' and 'stay outside' (Andrzejewski, 1960: 69). If there is also distributivity in the sentence the verb has a plural ending as in (4) from Wellega Oromo.

(3) dúri kúbl-éen sadí hammaatté (Borana Oromo) once.upon.a.time oxen-PL three:NOM become.bad:3F:PAST alá ggalte and stay.outside:3F:PAST

'Once upon a time, three strong oxen became bad and stayed outside.' (Andrzejewski, 1960: 69)

(4) dúbrii bíyya téennyaa múddhii qaq qál'-oo qáb-an (Wellega Oromo) girl.M:NOM country F:our waist PL thin-PL have-3PL

'The girls of our country have a thin waist.'

(Ali and Zaborski, 1990: 17)

The subject 'girl' is in the general number form but combines with a plural subject ending on the verb because of the distributive plural interpretation of the sentence that is imposed by the plural adjective modifying the objects. There is no plural marking on the subject but the interpretation of the sentence is one of a distributed multiple reference subject: every individual instance is valid. Verb inflection is linked to the semantics but not to the formal properties of the subject in terms of presence of number marking.

\subsection{MORPHOLOGICAL NUMBER MARKING}

Cushitic languages tend to have various different ways to form plural nouns. In most cases, the choice is lexically determined with quite some variation both across and

${ }^{2}$ Some K'abeena citation forms contain singulative suffixes but even in those cases they act as general number whether there exists an additional plural form or not. For example, the word maganu 'God' is a citation form base with no number marking while k'ariccu, another word for 'God', contains the singulative ending -iccu but is the only number form for this lexeme and both words act as general number (Crass 2005: 63-5). 
within speakers. The morphological marking of number on nouns involves rich systems with multiple derived singulative and plurative derivations for one and the same lexeme. In order to distinguish between the dimension of morphological number expression and the dimension of semantic value of number, I will use the terms singulative (SGTV) and plurative (PLTV) for morphologically derived number forms. The following examples (5) with words for 'gourds' in Konso illustrate the complexity of the system of morphological number marking in that language. The cover term dahaanaa has no number morpheme on it but is most commonly used for a plural concept 'gourds'; a singular gourd can then be derived with the singulative marker - $t a$. This renders the noun feminine, as each nominal number marker imposes a gender value. The value $P$ corresponds to plural gender; see section 25.6 for arguments in favour of treating plural as a category of gender. The derived singulative can be pluralized again with the very common plurative marker -addaa. The fact that dahaant-addaa is formed from the singular is evident from the retention of the $t$ of the singulative marker. This plurative of the singulative exists next to a plurative of the base with the same plural suffix. Although one could imagine semantic differences between the general form and the two plurative forms, no clear semantic differences seem to exist. This is equally true for the two competing plurative forms in (5b). What example ( $5 \mathrm{~b}$ ) also shows is that we can have a constellation in which both singular and plural contain a number suffix while they are not derived from each other but rather from a non-existing base; the virtual base murraa does not (possibly, no longer) exist. Example (5c) shows that not all singulatives can be pluralized. For each lexical entry it has to be specified which pluratives and which singulatives exist, but also what the number value of the base form is (neutral, singular, or plural).

(5) Derived number in words for 'gourds' in Konso
a. dahaan-aa (P) 'gourds'
$\rightarrow$ PLTV: dahaan-addaa (P)
$\downarrow$
SGTV: dahaan-ta (F)
$\rightarrow$ PLTV: dahaant-addaa (P)
b. murraa-ta $(\mathrm{F})$ 'gourd for drinking' $\rightarrow$ PLTV: murr-awwaa (P), murr-addaa (P)
c. shaww-aa (P) 'gourd with handle' $\rightarrow$ PLTV: shaww-addaa (P) SGTV: shaww-ayta (M)

Example (6) provides three lexemes with only one number form in Iraqw. The word tluway 'rain' can be used in a plural sense referring to several showers and triggers plural agreement on an adjective in that case, but it can also combine with a singular adjective and refer to one shower; this double value is typical for the transnumeral suffix -ay in Iraqw. Examples (6b) and (6c) show lexemes with one member referring to a singular and to a plural noun, respectively. The non-existence of derived pluratives for (6a) or derived singulative for (6b) is not dictated by the meaning of the lexical item and should again be specified. 
(6) Lexemes without number derivatives in Iraqw

a. tluway (M) 'rain' SG/PL

b. adoo (F) 'manner' SG

c. af $(\mathrm{P})$ 'scrapings of stiff porridge at the sides of the pot' PL

The complexity of these very diverse patterns of number formation is for some Cushitic languages further enhanced by the large amount of number formatives. For example, Alagwa has twenty-one plurative and eight singulative formations (Mous, 2016: 70-100). Pluratives of singulatives occur in patterns: for example, the singulative -imoo in Alagwa pairs with a plurative -ma'i as in laqay-moo (M) 'thorn, needle', PL: laqay-m-a'i (P) (Mous, 2016: 42).

The choice of which plural formation to use with a particular underived base correlates to some extent with the final vowel of that base, and that final vowel correlates to some degree with gender. In Alagwa the plurative formation of infixing the vowel $e e$ before the final root consonant and suffixing -oo is used with bases that are feminine, end in $i$, have a sonorant as their last stem consonant and have at least three stem consonants; while the plural formative of reduplication of the final consonant and a suffixing - $a a$ imposes feminine gender and is used with masculine bases that end in $u$. Such tendencies for the choice of the plurative morpheme correlating with gender and the final vowel of the base do not exist for the choice of singulatives. These correlations are the basis of a phenomenon that is known under the term of gender polarity which is discussed in section 25.4 .

Several functions can be expressed by pluratives on nouns: plural reference, reference to individuals in a group or multiple individuation, plural of kinds, distributive plurals and plural of contempt, exaggeration, and big size. When the plurative is a second derivation of a derived singulative, the meaning can be specifically a plural of individual specimens. For example, Iraqw magwál 'collarbone, stick with hook' has a singulative magwal-moo and a subsequent plural magwal-ma' which refers to a quantity of random unpaired individual bones or sticks. In Tsamakko, the plurative morphology implies high quantity when used with an uncountable noun ( $7 \mathrm{a})$, an inherently plural noun $(7 \mathrm{~b})$ and for the double derived plurative $(7 \mathrm{c})$.

(7) Tsamakko pluratives of plurals indicating high number

a. gam-e (F) 'maize'

b. innakk-o (p) 'flies'

c. mažo (M) 'cylindrical bead'
PLTV: gam-m-e (P) 'a great amount of maize' SGTV: gam-itt-o (M), gam-itt-e F 'little quantity of maize'

PLTV: innakk-add-e (P) 'exceptionally high number of flies'

PLTV: maž-ž-e (P) 'cylindrical beads'

PLTV: maž-ž-add-e (P) 'lots of cylindrical beads'

(Savà, 2005: 77, 85) 
In Kambaata, singulative markers can indicate individuation or singular reference but also empathy (when added to nouns that are already notionally singular), partitive (when added to mass nouns), or diminutive (when added to count nouns), see Treis (2008: 137-44).

The last two paragraphs described the range of meanings of the number formatives. These identified meanings were not contributed by a specific morpheme. However, Bayso has a dedicated paucal marker (Corbett and Hayward, 1987). Savà (2011: 183, 2017) argues that this is an instance of contact influence, pointing to the fact that the Omotic language Haro spoken on the same small island, has paucal as number value (Hirut, 2015: 42). In Omotic Hamar the only plurative formative has paucal meaning (Petrollino, 2016: 77).

Iraqw has two number suffixes (among a total of twenty-one number formatives) that can be paired with both singulative and plurative derivations, depending on the root:-aay $\mathrm{M}$ and -angw $\mathrm{M}$ (Mous, 1993: 46-7). The suffix -aay acts as singulative for 'dog', see'-aay (M), PLTV: see'-aawee (F), but as a plurative for 'bamboo' daa'-i (F), PLTV: daa'-aay (M).

I have used the term 'derivations' above suggesting that number formation is a derivational process rather than an inflectional process in these languages. Lecarme (2002) argues for a derivational approach to number in Somali. ${ }^{3}$ Since the inflectionderivation dichotomy is multidimensional it is necessary to investigate the properties that number formation really has. The following is modelled after Acquaviva's (2008: 21-43) discussion of non-inflectional plurals. Cushitic plural formation has properties that point towards derivation and towards inflection. Properties (1)-(4) are typical for derivation and atypical for inflection but properties (5)-(7) are less typical for derivation and common for inflection.

1. There is no obligatoriness of expression of number and thus there is no automatic interpretation of the unmarked form in terms of number; a base can be plural in meaning and have an additional plurative nonetheless, as in (5a). Languages differ though in how commonly plural-marked forms are used and differ in the default interpretation of a base for which a plurative exists.

2. Lack of generality: not every noun has a singular and plural form, ${ }^{4}$ and this extends to lexemes where there is no semantic reason for this, as in (6).

3. Lack of determinism: the same base can have several plural formations with no semantic differences ( 5 b), and there is variation in the choice, including for the same speaker. This is inevitable in languages with a high number of different plural formatives while plurals are rarely used. If several singulatives for the same base exist, they usually differ in meaning.

${ }^{3}$ The properties 1-7 below are general characterizations of Cushitic that may not be valid for every individual language.

${ }^{4}$ Konso is different in this respect; a plurative can always be added to a base and will induce a multiple reference interpretation (Ongaye Oda Orkaydo, p.c., 15 August 2019). 
4. Stacking of derivation: pluratives of pluratives are possible $(7 \mathrm{c})$; but also pluratives of singulatives ( $5 \mathrm{a}$ ), but not singulatives of derived pluratives.

5. Different plural formations rarely have different semantics (5b).

6. It is very rare that a number form develops an unpredictable new meaning; that is, lexicalization does not occur, and the different number forms of the same lexeme form a unit in the lexicon. The semantic differences that were listed above come about through interplay of lexical semantics, number meaning, and competing forms within a lexical paradigm.

7. Singulative and plurative derivations impose values for agreement in Number, but also in Gender.

\subsection{APPARENT GENDER POLARITY: THE CASE OF SOMALI}

Since Meinhof (1912) Somali has served as a prime example for gender polarity to express number: masculine nouns are feminine in the plural and feminine nouns are masculine in the plural $(8 \mathrm{a}-\mathrm{d})$ with $(8 \mathrm{e})$ as exception.

(8) Somali polar gender
a.àwr $M$ 'male camel'
áwr F 'male camels'
b.sánnad $\mathbf{M}$ 'year' sannaddó $F$ 'years'
c. hóoyo F 'mother' hooyóoyin M 'mothers'
d.galáb F 'afternoon' galbó $M$ 'afternoons'
e. wán M 'ram'
wanán $\mathrm{M}$ 'rams'

(Saeed, 1999: 55)

The assignment of Somali nouns to a gender is based on nominal constituent internal agreement of definite markers; the picture of external agreement of the subject on the verb is more complex.

Exceptions occur and Meinhof (1912: 171) noted that the polarity does not hold for the plural formation by reduplication of the final consonant which he considered to be distributive (8e): masculine nouns that take reduplication as a plural strategy are also masculine in the plural. Second, there is a number of $M$ nouns that build a $M$ plural in $-o$, and, third, the plural formation -yaal shows regional variation whether it renders the plural $\mathrm{M}$ or $\mathrm{F}$; the singular being commonly $\mathrm{M}$ (Lecarme, 2002: 118-19).

Lecarme (2002) rejects polarity as the underlying principle for plural formation in Somali because in her view plural formation is a derivational word formation process and the seven plural formations each impose their gender value on the resulting plural. There are correlations between the choice of the lexical plural suffix and the gender value (and phonological shape) of the base which result in polarity in many but not all 
instances. She analyses Somali plural formation in the framework of Distributed Morphology and gives nominal value to the plural morphemes ('little $n$ ') with its inherent gender, overriding the gender of the lexical base. Kramer (2015: 147-66) likewise analyses Somali number formation within the Distributed Morphology framework as nominal in nature with gender specified on the number formative ('little $n$ ') and not on a Number node, as it would be in languages with inflectional number such as Spanish. Also Wunderlich (2012: 183) does not accept Somali number as fundamentally polar given the counterexamples that exist. However, Lahne (2007) formulates the idealized polarity structure of Somali in a formal feature model. I refer to Baerman (2007) for a principled discussion of the problems in using the concept of polarity in a theoretical approach and the use of the concept of markedness in analysing polarity. ${ }^{5}$

Nilsson (2016) renounces gender polarity for Somali on more principled grounds as he argues that Somali does not have gender distinction in the plural on the basis of the fact that the gender agreement that is referred to above is found for modifying suffixes that are located on the noun itself while all other agreement patterns on verbs and pronouns have only one form for plurals. Nilsson argues that if gender is evidenced by behaviour of associated words, then the behaviour of the noun itself and its suffixes is not enough for postulating a gender difference in the plural and he considers Somali to be similar to the Agaw (Central) Cushitic languages (and Russian and German) in terms of gender and number constellation.

Among the Cushitic languages with two values for gender, three constellations occur: all plurals are feminine, all are masculine, or plurals can have both values and there is some polar gender. The system in which all derived plural forms trigger feminine marking on the verbs is found in K'abeena (Crass, 2005: 65), Alaaba (Schneider-Blum, 2007: 57), and Sidaamo (Kawachi, 2007: 398). The system in which all derived plural forms have masculine agreement on the verb occurs in Dhaasanac (Tosco, 2001: 85-9, 112) and in the closely related Elmolo (Heine, 1976: 285). Note that in Dhaasanac $\mathrm{M}$ agreement on the verb is also triggered by the thirdperson plural human pronoun. ${ }^{6}$ The third system of $\mathrm{M}$ or $\mathrm{F}$ agreement for plural nouns depending on the plural formation occurs in Somali if we include the minor paradigms of number formation, and in 'Afar where plural nouns take masculine or feminine agreement, often different from their base and largely correlating to the quality of the final vowel of the noun (Bliese, 1981: 122-3; Hayward and Corbett, 1988: 265;

${ }^{5}$ But also containing a plea that systematic morphological reversal does exist in natural language. Serzisko (1982) analysed Somali gender and number as a gender polarity system, acknowledging idiosyncrasies. He considers polarity as one of the possible systematic means to reduce the number of markers in a case of fusion of two binary oppositions, here gender and number. Adding the concept of markedness, polarity equals the use of the marked form of an opposition for the marked form of another opposition: the marked gender $\mathrm{F}$ form can be used for the marked number plural. This explains the $\mathrm{M} \rightarrow$ $\mathrm{F}$ polarity; the $\mathrm{F} \rightarrow \mathrm{M}$ polarity requires the principle of markedness reversal to explain the fact that the unmarked gender $\mathrm{M}$ form is used for marked number value plural; in the marked context of plural the markedness value is reversed. See also Lampitelli $(2013,2017)$ for an analysis of Somali gender.

6 There are in fact only two forms in the inflected verb paradigm: the ' $M$ ' form is also used for $1 \mathrm{SG}$, 1PL.INCL, 3PL, and the ' $F$ ' form for 2SG, 1PL.EXCL, 2PL (TosCo, 2001: 112). 
Hayward, 1998: 628-9). ' The system familiar from languages like Spanish with gender stable across singular and plural forms of a lexeme does not occur in Cushitic.

The term gender polarity is used in Semitic studies for the phenomenon that feminine numerals are combined with masculine nouns and the other way around (Hetzron, 1967). Cardinal numbers from 3 to 10 take the opposite gender of the noun they combine with: masculine nouns take the feminine form of the numeral, feminine nouns take the masculine form of the numeral. Hetzron (1967) views polarity of gender expressing number in nouns as we see it in Somali as the source for gender polarity in such number constructions in Semitic.

\subsection{NUMBER AGREEMENT}

Across Cushitic we find two configurations that may display number agreement: modifying adjectives and subject-verb agreement. Whenever there is number agreement, this has only two values. Number agreement occurs on adjectives in some Cushitic languages but is not rigid in two different ways: agreement is not automatic but optional in Kambaata, as in (9a) the adjective, 'empty', has no plural marking but in (9b) the adjective 'full' does in very comparable contexts with both head nouns derived pluratives.

a. on-áta ma’nn-aakk-áta b. wiim-m-áta sawwitt-aakk-áta (Kambaata) empty-F.ACC place-PL2-F.ACC full-PL1-F.ACC thought-PL2-F.ACC 'blanks [lit. empty spaces]' 'sentences [lit. full thoughts]' (Treis, 2012: 266)

Second, with general number words in Iraqw there is choice of singular or plural adjectives as in (10) with plural marking forcing a distributive interpretation for each of the 'notes of paper money' while the singular adjective refers to the collection.

(10) Iraqw

$\begin{array}{lll}\text { notóo úr } & \text { /paper.money (notes) big/ } & \text { 'a lot of money' } \\ \text { notóo ur-én } & \text { /paper.money (notes) big-pL/ } & \text { 'large denomination notes' }\end{array}$

Some Cushitic languages show subject agreement on the verb that is not at all with number and strictly with gender only; others have a more common constellation with a combined gender and plural subject marking on the verb. Let me first give some general properties of gender in Cushitic. Cushitic languages have either two or three values for gender. Masculine and feminine can be used as labels for gender and all the languages have some areas of lexicon and grammar where natural and grammatical gender run parallel. However, for most lexical items, gender is not semantically

7 'Afar only has a two-value gender system if we discard the exceptions of the pronoun 'they' and three words for human subjects, 'people', 'children', 'women', which have plural marking on the verb. 
motivated and counter-intuitive examples can easily be found, such as Konso 'okatta (M) 'cow' (Orkaydo, 2013: 107), Dhaasanac sé (M) 'cow', Dullay ló'o (M) 'cow' (Amborn et al., 1980: 85), Dhaasanac yáb (F) 'males' (Tosco, 2001: 73), Oromo dúbra (M) 'girl(s)' (Stroomer, 1987: 72). Every noun has a gender value and as a rule only one. ${ }^{8}$ Different number forms within the same lexeme typically have different gender values because number-marking morphemes, singulatives, and pluratives impose their inherent gender on the noun. For example, Dhaasanac rúbba (F) 'sorghum' has a singulative rubbuti $(\mathrm{F})$ and a plurative rubb-anu $(\mathrm{M})$ as these number suffixes impose their gender (Tosco, 2001: 75, 79, 83).

Gender is defined as a property of a class of nouns that takes the same agreement forms: agreement within the noun phrase is diagnostic of the gender of the head noun. Agreement with the gender of a head noun occurs within the noun phrase for demonstrative, possessive, and other modifiers. In (11) the definite suffixes differ according to the gender of the head noun to which they are attached, and in Burunge the linkers preceding the possessive suffix agree in gender (12).

(11) Xamtanga gender sensitive definite suffixes
a. gilwä-dyän
b. fič’irä-šän
man.M-M.DEF
goat.F-F.DEF
'the man $(M)$ '
'the goat (F)'

(Darmon, 2015: 75-6)

(12) Burunge possessive suffixes with gender sensitive linkers
a. saga-go-si
b. fara-do-si
c. ma'ay-ko-si
head.M-M-3SG.Poss
bone.F-F=3SG.POSS
water.PL-P-3SG.POSS
'his/her head'
'his/her bone'
'his/her water'

(Kiessling, 1994: 83)

Crucially, in many Cushitic languages subject agreement on the verb is with gender only and not with a specific agreement form for plural number. This is the case in Dhaasanac where plural noun phrases and plural pronouns have $\mathrm{M}$ agreement (Tosco, 2001: 83-5), (13a).

(13) Dhaasanac subject agreement (underlining indicates focus)

a. masam $=u$ badai

ropes $=$ FoC get.lost:Pr.M

'The ropes got lost.'

b. ?ár=ru diyyime

bull=FOC make.noise:IMPF:M

'The bull is making noise.'

(Tosco, 2001: 271)

${ }^{8}$ There are exceptions to this: gender can differentiate sex typically in words for domestic animals and in personal names. In addition, some languages show secondary use of feminine gender to express small size, e.g. Kemant šär-ay nüy/good-REL.M house/'a house which is good' but šär -ey nïg/good-REL.F house/'a little house which is good', Zelealem (2003: 228). See Di Garbo (2014) on this phenomenon. 
The situation is similar in K'abeena where all plurals have the same agreement as F on the verb (Crass, 2005: 157). An alternative approach is to analyse Dhaasanac as showing masculine-plural syncretism and K'abeena as showing feminine-plural syncretism. Such a syncretism analysis is warranted in a view that privileges number agreement above gender agreement on the verb and that considers gender to be linked to the lexeme rather than to the individual word form. For other languages, the syncretism analysis is more problematic. Iraqw for example has $\mathrm{M}, \mathrm{F}$, and $\mathrm{P}$ pluratives-and plurative nouns can trigger values for subject agreement on the verb. For a language with this configuration, an analysis that takes the M, F, and P agreement on the verb to be gender agreement is more straightforward than one of mixed gender and number agreement and syncretism(s). In the following examples from Iraqw baris$e e$ 'elders' $(14 \mathrm{a})$ is the plurative triggering feminine agreement on the verb while its singulative bariis-mo would have triggered masculine agreement. In (14b) the plurative deel-áy (M) 'kids' (singulative being deel-mo $\mathrm{M}$ ) triggers masculine agreement. In (14c) $n a S-i i$ 'children' is the plurative of naSaay 'child' and triggers plural agreement while its base naSaay would have triggered masculine agreement.
a. baris-ee
masamba
ng-a-na
yaSáb
elders-PL(F) youth(F) PL:O3-O.F-PAST send:3F
'The elders sent the youth.'
$\begin{array}{lll}\text { b. deel-áy } & \text { tlarángw } & \text { Say } \\ \text { kids-PL(M) } & \text { powder:M:CoN } & \text { eat:3M }\end{array}$
'The children are eating the flour.'
c. naS-'ii daxa naa urar-é'
child-PL(P) now PL:3:PF grow:IMPFV-3P:PF
'The children were now grown.'

\subsection{PLURAL AS GENDER VALUE}

In the preceding, we have used Plural as a value for gender. In this section, I explain the reasoning behind the use of the term plural and argue that some alternative approaches cannot account for the data in a satisfactory manner. I will use $P$ for the value of gender and PL for the value of number. These values are not identical. I illustrate this property with Konso. Konso nouns can be divided into three groups on the basis of subject agreement of nouns: the verb forms for $3 \mathrm{M}, 3 \mathrm{~F}$, and $3 \mathrm{P}$ as in (15).

a. Goyra-si? $\mathrm{i} i=$ Gep-ay

(Konso) tree-DEF.M $/ F \quad 3=$ be.broken-PF $[3 M]$

'The tree was broken.' 

b. harreeta-si? $\mathrm{Pi}=$ Gep-t-i
donkey-DEF.M $/ \mathrm{F} \quad 3=$ be.broken-3F-PF
'The donkey was broken.'

c. filaa-sini? poor-aa? $\mathrm{i} i=\mathrm{Gep}-\mathrm{i}-\mathrm{n}$

comb-DEF.P black-PL $3=$ be.broken-PF-3P

'The black comb was broken.'

The verb form for subjects like 'donkey' in (15b) is used with the pronoun 'she'; the one for subjects like 'comb' in (15c) is used with the pronoun 'they' and the one for subjects like 'tree' in (15a) is used with the pronoun for 'he' (the base form of the verb); hence the labels F, P, M. The subjects in (15) are all singular in reference. Multiple reference forms that are derived by one of the seven plural formations are $\mathrm{P}$ in gender in Konso, but note that in Cushitic languages that lack a third gender, plural derivations are either $M$ or $F$ depending on the language The Konso multiple reference words that are not derived are $M$ or $P$. The noun orra 'people' $(16 a)$ is multiple in reference as is clear from the plural number agreement on the adjective; the gender agreement on the adjective is merged $M / F$ and clearly $M$ for subject agreement on the verb in ( $16 \mathrm{~b}$ ).
a. orra-si?
people-DEF.M/F
PL be.fat $-M / F$
in $=a k k-a y$
$1=$ see- $P F$
'I saw the fat people.'
ka kapp-a
b. orra-si?$$
\mathrm{i}=\mathrm{kal}-\mathrm{ay}
$$
people-DEF.M/F $3=$ return.home-PF[3M]
'The people returned home.'

If we accept that agreement on the verb is purely with gender and define gender on the basis of agreement, Konso has three groups of nouns, which trigger masculine, feminine, and plural agreement on the verb. The agreement is predominantly dictated by the formal gender property of the triggering noun and not based on semantic notions. As such the agreement classes could also be labelled 1, 2, and 3 or A, B, and $C$. However, in the less common situations that agreement has a semantic base, this is with male, female, and plural. For example, Iraqw names require $\mathrm{M}$ or $\mathrm{F}$ agreement on the verb depending on the sex of the referent, also when male and female names are identical. Iraqw 3 sG pronoun inós refers only to humans but is not distinguished for gender and triggers masculine or feminine agreement depending on the sex of the referent. Its plural third-person pronoun is ino'in which requires plural agreement. As with feminine and masculine, plural gender is a formal property of the noun, which is not predictable on the basis of semantics.

Corbett (2012: 223) brings up a fundamental objection to having plural as a value for gender. It violates orthogonality or the exclusiveness principle that a value belongs to just one feature. He has offered an alternative analysis of Bayso (Corbett and Hayward, 1987; Corbett, 2012: 224-33), a language that was previously analysed with P as a value 
for gender by Hayward (1979). The alternative analysis takes the general P nouns as pluralia tantum nouns that take 3PL agreement on the verb. This 3PL agreement is considered a value of number. Furthermore, Corbett's alternative analysis does not consider number to be derivational and allows only one gender value per lexeme; derived singulatives have the same gender as their base in Bayso (and differ from other Cushitic languages in that respect) and derived plurals take $\mathrm{m}$ agreement. The instances where derived plurals require $\mathrm{F}$ and $\mathrm{P}$ agreement are further exceptions. The numbers of exceptions are small. We have to take into account that in fact the description of Bayso is insufficient and any analysis of the language should be considered as preliminary given that the data were collected in a seventeen-day fieldwork period, albeit by a highly competent field linguist, Richard Hayward.

If we try an alternative analysis along similar lines for Konso we need to allow for a class of exceptional pluralia tantum nouns which contains roughly 20 per cent of the underived nouns. A list of 664 underived Konso nouns with no number suffixes contains $128 \mathrm{P}$ nouns or 19 per cent, $351 \mathrm{M}$ nouns ( 53 per cent), and $185 \mathrm{~F}$ nouns (28 per cent) (Orkaydo, 2013). The underived $\mathbf{P}$ nouns form a minority but a group that is too large to treat as exceptions.

A more serious challenge is the fact that Konso has both number and gender agreement in separate exponents of the adjective. If the P nouns were marked to trigger number agreement they would result in conflicting values on one and the same adjective modifying the same controller. For example, the P word for 'comb' in (14c) takes an adjective 'black' with no initial reduplication because it is singular in number but with the plural suffix - aa? for gender agreement (Orkaydo, 2013: 79). The independent and different agreement of number and gender on adjectives also shows that there is indeed a need for orthogonality. We cannot take the value $\mathrm{P}$ for gender as the same value as the value PL for number. But analysing the P words in Konso (and the other languages with $\mathrm{P}$ gender) as pluralia tantum words with only number agreement and no gender agreement does not work for this reason of different and independent agreement of number and gender on adjectives.

Another indication why P should be taken as a gender value is the fact that gender marking M, F, P often forms one morphological system in various Cushitic languages. For example, Amborn et al. (1980: 85) argue for the Dullay languages that gender and number form one morphological category because there is one set of final vowels ( $o$ for masculine, $e$ for feminine and plural). This argument can be extended to many other Cushitic languages, in Rendille, for example M, F, and P nouns behave as one paradigm for case expression (Pillinger and Galboran, 1999: 21); in Iraqw object agreement is in gender by the choice of a vowel in the same slot: $u(\mathrm{M}), a(\mathrm{~F}), i(\mathrm{P})$.

Psycholinguistic research has shown that the third value of gender, plural, behaves in a comparable way to the other values of gender, masculine and feminine, in terms of a gender congruency effect for reaction times when producing gender-marked forms in picture-naming tasks with audio distractors with same or different gender. Audio distractors with the same gender as the target resulted in significantly shorter reaction 
times for all three genders, as expected under the hypothesis that $\mathrm{P}$ functions as a value of gender in Konso. See Tsegaye (2017); Chapter 6 in this volume.

There are other Cushitic languages with the more familiar gender and number agreement on the verb with gender only differentiated in the singular. The Agaw languages are of that type. In the Agaw language Xamtanga, nouns that have multiple reference are marked with one of the various plural marking strategies and require the third-person plural ending on the verb for subject agreement. Some mass nouns have a choice between singular and plural agreement on the verb. Gender is only distinguished in singular nouns and restricted to sex-differentiated nouns; in Xamtanga there are no semantically plural nouns triggering $M$ or $F$ agreement on the verb and no semantically singular nouns triggering plural agreement (Darmon, 2015: 66, 69ff.).

The rare property of $\mathrm{P}$ as a value for gender can be understood in a situation in which agreement on the verb is formal and not semantically motivated while different number forms within the same lexeme have their own gender. The emergence of $P$ for gender is linked to the verb agreement as a formal automatic process, as syntactic agreement. A two-gender language like Oromo (close relative of Konso) shows number agreement on the verb. The paradigm has three forms available for lexical noun phrases and it has nouns that require formal 3PL agreement on the verb while the 3PL verb form is otherwise only used for situations in which the subject is semantically plural and the action distributed; that is, it is strongly semantically motivated. In (17) the subject nadieeni is a general noun of $\mathrm{F}$ gender but with $3 \mathrm{PL}$ agreement on the verb hobobsisani because of the reciprocal meaning, but in the second clause the same subject occurs with $\mathrm{F}$ agreement on the verb dal-tî̀ 'come-3SG.F' where the action is not reciprocal. However, there is a set of nouns ending in $a(a) n i$ in Borana Oromo that require plural agreement while some of them have singular reference (18). The suffix $-a(a) n i$ is also one of the plural noun suffixes; moreover, the third-person plural ending on the verb is -ani.
nadd'ièeni ofî yó hobobsis-áni, námaa akkasáti dal-tî. woman cohabit-3PL person come-3sG.F
(Oromo) 'If women were to cohabit carnally among themselves, they would produce such men.'

(Cerulli, 1922: 191)

$$
\begin{array}{lll}
\text { bisaani } & \text { bokayaa } & \text { hobbaani } \\
\text { water } & \text { rain:LIN.GEN } & \text { be.finished:3PL.PAST }
\end{array}
$$

'The rainwater became exhausted.'

(Borana Oromo)

(Stroomer, 1995: 41, quoting Andrzejewski, 1962: 126-7)

The Borana Oromo situation looks like a two-way gender system and a set of pluralia tantum words with $3^{\mathrm{PL}}$ agreement. At the same time they trigger $\mathrm{M}$ (some $\mathrm{F}$ ) in their noun phrase internal agreement on demonstratives and possessives; thus we cannot claim that they are $\mathbf{P}$ in gender comparable to related Konso.

In Somali, mass nouns do not have different number forms and those that end in $\sigma$ which is one of the plurative suffixes, take 3 PL agreement (pluralia tantum forms) while 
the other mass nouns take $M$ or $F$ agreement (Saeed, 1999: 57). Thus, the external agreement on the verb is $3 \mathrm{PL}$. for nouns that are considered frozen pluratives. Nouns that do not have a segmental suffix for plural formation but only tone shift-which is otherwise a means to render nouns feminine-are collectives and allow $\mathrm{F}$ agreement on the verb. Nouns that are not derived for number take $\mathrm{F}$ or $\mathrm{M}$ agreement on the verb; including the transnumeral nouns that can have a plural interpretation. The $3^{\mathrm{PL}}$ agreement for nominal subjects is hence not purely semantic, and formal properties play a crucial role.

It is likely that the source for $\mathrm{P}$ gender words is indeed in pluralia tantum words. Investigating the semantics of underived lexical $\mathrm{p}$ nouns in Konso one can discern some plurality in a broad sense in the meaning. Some liquids are $\mathrm{P}$, and abstract words like 'culture', 'language', 'light', items that come in quantity or in pairs, 'faeces', 'money', items with internal structure 'comb', or patterns 'tortoise', body parts in pairs 'lungs', but also words for 'machete', 'enemy', 'liver'. Comparison with other languages that have the $P$ gender value reveals that some of these semantic characterizations are found there as well. Van der Meer (2015) in her study of the semantics of Cushitic ( $P$ ) words finds unboundedness and internal structure as recurrent but non predictive semantic features, see also Acquaviva (2008) for a discussion of the semantics in general of pluralia tantum words.

All the languages with three values for gender display gender agreement on the verb. There are no languages with three values for gender in internal noun phrase agreement and number agreement on the verb. Quite often those languages that have a three-way gender on the verb show gender syncretism in the internal agreement within the noun phrase. For example, in Iraqw and Alagwa, possessive and demonstrative pronouns distinguish $\mathrm{M} / \mathrm{P}$ versus $\mathrm{F}$ (Mous, 1993, 2016). These are all indications that the emergence of $\mathbf{P}$ gender is in formal agreement on the verb.

\subsection{CONCLUDING REMARKS: THE NATURE OF NUMBER AGREEMENT}

Number and gender are generally very different features of a noun. Gender is often an inherent and invariant feature of the noun while number is accorded to the noun in the formation of the utterance: 'It is not characteristic for a noun such as mother, house, etc. to appear in the singular or plural form, this feature specification therefore is introduced by the syntactic rules of the base' (Bierwisch, 1967: 242, as quoted in Serzisko, 1982). The Cushitic anomalies of gender and number can be understood from this general characterization. Let us therefore review and compare the agreement phenomena and specifically agreement on the verb.

While gender is a formal property of the noun in Cushitic, linked to the morphological word form and not the lexeme with agreement functioning to show which 
words in the sentence belong together, number is a semantically loaded category which expresses individuality or lack thereof and showing semantic motivation and expression in non-automatic or non-morphological agreement.

Number marking on the adjective in several Cushitic languages is expressive rather than automatic agreement and brings out an interpretation that brings out a set of individual items. ${ }^{9}$ Number agreement on adjectives is not always automatic and can be optional as in example (9) from Kambaata in which the adjectives 'empty' and 'full' are used in comparable contexts expressing metalinguistic concepts such as 'blanks/spaces' and 'sentences', once with plural marking and once without plural marking on the adjective while both head nouns are plural in reference and marked as such. In the Iraqw example (10) plural marking on the adjective forces an interpretation of the noun notay 'paper money' as a collection of separate bank notes, each being 'big' or 'high denomination'; this head noun is not specified for number. The number agreement on the adjective seems necessary when the quality is meant to be valid for all individuals.

Number marking in adjectives is similar to pluractionality in verbs in this respect and in a language like Konso the marking is also the same reduplication. Example (16a) shows initial $\mathrm{CV} \sim$ reduplication for plural number agreement on the adjective for 'fat' in Konso; the Konso pluractional verb is formed by the same initial CV reduplication, as in $2 i$ Go $f o f \int t i$ 'she pinched a few times' (Orkaydo and Mous, 2017). Like the double agreement of gender and number on adjective, Konso also shows a double agreement of gender and number on the verb. Subject agreement is automatic and with gender, as shown in (15). In addition to that, verbs have a reduplicated pluractional form to express that the event is plural. The absence of such reduplication forces a reading that the event is singular, just like in adjectives in (10), see Orkaydo and Mous (2017) for an analysis of event number in Konso.

The general picture that emerges is that some of the Cushitic languages have lexemes with a number of different forms that do form a paradigm with a single lexical meaning but with different conceptualizations in singular reference, general number, multiple reference, sometimes others. Each of these forms has its gender value, $M / F$ or $M / F / P$, depending on the language, either imposed by the derivational number morphology or inherently linked to the base. These gender values are borne out by agreement.

In a language like Iraqw, both derived and underived nouns can have any gender. Plurative suffixes induce their gender onto the noun and this can be masculine, feminine, or plural. Non-derived nouns too can be either masculine, feminine or plural. In Iraqw, nouns are not number neutral in their underived base form, most are singular in their base form but some are plural in number and those plural bases too can be either masculine (58), feminine (25), or plural (4). The numbers in brackets refer to the amount of such nouns in my dictionary files. Some loans are taken over as plural, e.g.

\footnotetext{
${ }^{9}$ Nilsson (p.c.) points out that in Somali corpus data one can find a singular noun like muraayad 'mirror' or Ingiriisigiisa 'his English' and an adjective like jajaban 'broken' in the 'plural', as the mirror is broken into several pieces and 'his broken English' is not just broken once, 'into two pieces', but is characterized by a number of faults and error distributed throughout his production in English.
} 
chupa (f) 'bottles' from Swahili chupa 'a bottle'. This illustrates that gender is a category that operates quite independently from number and that the common situation in number that singular is default and plural derived is less valid in the morphological marking of number of Iraqw and some other Cushitic languages.

The category of individuality and plurality (number) is not prominent in agreement but has expressive function in the semantic conceptualization of the entity (in adjectives) or the event (in verbal pluractionality). 


\title{
THE OXFORD HANDBOOK OF
}

\section{GRAMMATICAL NUMBER}

\author{
Edited by \\ PATRICIA CABREDO HOFHERR \\ and \\ JENNY DOETJES
}

